DOI 10.37882/2500-3682.2021.05.07

ФИЛОСОФИЯ «ТИК-ТОК» - НОВЫЙ ДИСКУРС МЕДИАЛОГИИ

THE PHILOSOPHY OF TIK-TOK AS A NEW DISCOURSE OF MEDIALOGY

D. Bozhedarov

K. Kalikanova

Summary: The formation of the network telecommunications space is happening rapidly. For this process, geographical and temporal indicators do not play any role. And, what is most important for assessing the functioning of network communication - its «activists» practically do not experience any institutional restrictions. Accordingly, the idea of social, ethical and aesthetic norms is formed under the pressure of the mechanisms of formation of the image of the personality of the network actor.

One of the most striking manifestations of the network media communication space is Tik Tok. This application combines the functionality of Instagram and Snapchat, which are popular all over the world. The main task and opportunity in this social network is to create videos. Basically, videos are clips, sketches, or reactions to trends. It is also possible to conduct live broadcasts. Tik Tok first appeared in China in 2016.

Keywords: media communication, media space, network communication, trend, clip, sketch.

\author{
Божедаров Дмитрий Александрович \\ К.филол.н., доцент, Национальный Исследовательский \\ Мордовский университет им. Н.П. Огарева \\ db13@rambler.ru \\ Каликанова Ксения Игоревна \\ Национальный Исследовательский Мордовский \\ университет им. Н.П. Огарева \\ kalikanova_k@mail.ru
}

Аннотация: Формирование сетевого медиакоммуникационного пространства происходит стремительно. Для данного процесса, не играют никакой роли географические и временные показатели. И, что самое важное для оценки функционирования сетевой коммуникации - ее «активисты» практически не испытывают на себе институциональных ограничений. Соответственно представление о социальных, этических и эстетических нормах формируется под давлением механизмов становления образа личности сетевого актора.

Одним из ярких проявлений сетевого медиакоммуникационного пространства является «Тик ток». Это приложение, по функционалу совмещающее в себе популярные во всем мире Instagram и Snapchat. Основной задачей и возможностью в этой социальной сети является - создание видеороликов. В основном ролики представляют собой клипы, скетчи или реакции на тренды. Так же есть возможность вести прямые эфиры. Впервые «Тик ток» появился в Китае в 2016-ом году.

\section{Цель исследования.}

- определить место явлению «Тик ток» в сетевой медиакоммуникации;

- определить предпосылки появления площадки «Тик ток» в современной цифровой медиакоммуникационной системе;

— определить основной мотивационный аспект функционирования и развития медиасетевого движения «Тик ток»;

- определить типологические особенности данного явления медиакоммуникационой цифровой системы;

Ключевые слова: медиакоммуникация, медиапространство, сетевая коммуникация, тренд, клип, скетч.

ролики, которые завоевывают интерес молодых пользователей;

- отсутствие значения социального статуса и материального достатка;

- присутствие значения творческих способностей «добывания» лайков и просмотров.

Важность причин в функциональных основах подчеркивает в своих учениях Рене Декарт, утверждая, что «Причина никогда не может быть меньше, чем действие, а должна содержать в себе больше или столько же реальности, сколько и действие» [1, с.204].

Интересен тот факт, что результаты нашего исследования показывают, что не сам контент, а онтологические условия Тик тока, его диалектика и эволюция строятся согласно Закону пятиактной драмы, который уходит своими корнями в эпоху Аристотеля [2, с.19]. 


\section{Актуальность}

Выражается, прежде всего, в том, что, не требуя практически никаких титанических усилий от акторов, площадка открывает перед ними безграничные возможности публичной самопрезентации, с учетом прочной фиксации в цифровом медиакоммуникационном пространстве. Подобная коммуникативная свобода требует от актора особого уровня социальной ответственности, а от исследователей сетевого медиапространства - глубокого изучения с целью определения возможностей управления данным коммуникативным потоком во избежание антисоциальных последствий. Тем более, что грань между виртуальной реальностью и реальным миром в условиях «Тик тока» весьма тонка и ее стирание может привести к непрогнозируемым последствиям. Специфика современной виртуальности не случайно привлекает большое число различных исследователей (И.М. Дзялошинский, Е.И. Ярославцева, Н.Б. Маньковская и др.) Системным выводом является то, что воплощение специфики виртуальности становится интерактивность. Она позволяет различные творческие проявления. Созревшие в сознании акторов, воплотить в реальных воздействиях, которые переводят аудиторию из пассивного статуса в статус сотворца [3, с.311].

Площадка «Тик ток» позволяет подросткам достичь финансового успеха сравнимого с активностью предпринимателей высокого уровня, поскольку формируя контент, «тик токеры» являются объектом интереса для рекламодателя. В зависимости от количества подписчиков возрастает и экономическая обоснованность рекламного участия на фиксированных в медиапространстве, страницах. Исследуя онтологию медиакоммуникационного пространства, его цифровую зону, авторы данного исследования приходят к выводу о том, что, последнее, являясь субстаниией, построенной на совокупности необходимых условий для осуществления коммуникативных функцией, является практически безбарьерной средой для деятельности акторов «Тик тока». Одной из отличительных признаков данной безбарьерной среды является отсутствие институциональных ограничений в деятельности. Конечно, отдельные попытки ограничений все же имеют место, но системного подхода к решению данной проблемы пока еще в правовом поле нашего государства не существует.

Таким образом, цели, поставленные перед данным исследованием, могут быть достигнуты посредством решения следующих задач:

- определить уровень возможности установления популярности в «Тик ток»;

- выявить основные причины возникновения взаимного интереса в отношениях с рекламодателем;

- определить некоторые маркетинговые алгоритмы развития «Тик ток» в цифровом медиакоммуникационом пространстве;
- определить ресурсные возможности «Тик ток» продвижения продукции и услуг.

\section{Научная новизна}

Заключается в том, что авторы исследования впервые осуществляют попытку теоретического осмысления такого события в сетевом медиакоммуникационном пространстве, как «Тик ток». Авторы впервые определяют системные и структурные особенности «Тик тока», как коммуникационного явления. Авторы так же систематизируют некоторые функциональные возможности явления «Тик ток». Осуществляют попытку прогнозировать предпосылки и вектральность дальнейшего развития платформы «Тик ток».

\section{Методы и методология исследования}

В связи с тем, что в настоящее время практически отсутствует база теоретических обобщений накопленного знания в области «Тик ток» - коммуникации, авторы исследования используют методы общенаучного подхода к анализу процессов, применяется метод экстраполяции, сопоставления и сравнительного анализа. Особенно эффективным в данном случае явился метод системного наблюдения.

\section{Результаты исследования и их обсужление}

Основой «Тик ток» является лента приложения с «Рекомендациями». В ней показываются основные тренды, самые популярные видео, актуальная музыка и так далее. Одной из самых важных особенностей этой социальной сети является то, что данная платформа сама занимается продвижением в рекомендациях молодых и перспективных контентмейкеров. Таким образом, например, человек с миллионами подписчиков и огромными охватами и пользователь, который только попал в «Тик ток» имеют одинаковые шансы на то, чтобы стать популярными и появится на глазах миллионной аудитории. Все зависит от качества контента и отклика пользователей (лайки, комментарии, просмотры, число поделившихся и т.д.)

Благодаря «Тик ток» любой бренд или же рекламное лицо может контактировать с огромной «живой» аудиторией. Неудивительно, что крупные бренды уже почувствовали перспективы. На «Тик ток» ведут каналы такие «монстры бизнеса», как"Сбербанк", «Nike», «Apple Music», "Билайн" и другие.

Данные, полученные в ходе исследования, позволяют нам выделить 3 главных причины рекламироваться и продвигать себя либо же собственный продукт на платформе «Тик ток»:

Большой потенциал. Пока рекламы в этой социальной сети не так много, и она грамотно представлена так, 
чтобы не мозолить глаза зрителям и потребителям контента, то можно запросто привлечь внимание к своему бизнесу. И, наверное, самое важное - сейчас «Тик ток» разрабатывает функционал для онлайн-покупок, что позволяет его еще больше рассматривать как действительно успешную рекламную площадку.

Но любому, кто решит воспользоваться данным приложением для продвижения и продаж, стоит обратить внимание на возрастную категорию, заинтересованную в вашем так называемом «продукте», потому как половина аудитории здесь младше 20 лет. Если вы продвигаете потребительские кредиты или страхование жизни, то платформа вам не подойдет, но вот для FMCG сектора, брендов одежды, рэп-исполнителей - это буквально золотое дно.

Алгоритмы в «Тик ток» по своей работе очень похожи на алгоритмы Instagram, но все же со временем аудитория заметила, что они продуманы намного лучше. Если пользователь интересуется исключительно историей и танцами, то, скорее всего, его рекомендации будут заполнены познавательными фактами и хореографией.

В «Тик ток» отлично продумана система реакции на контент, создаваемый авторами роликов. Такая система вовсе не новая, она применялась уже и раньше на других похожих платформах. Суть, естественно, в лайках, комментариях и в некоторой степени репостах. Таким образом, раньше в том числе и отметка «мне нравится» не обещала выдачи в последующей как раз такого контента, которые вправду интересен и необходим. В «TikTok» же с поддержкой лайков и репостов круг предпочтений крепко конкретизируется. Особенно интересно то, что данная платформа не просто засчитывает просмотр, а фиксирует время, затраченное на этот ролик. Так получается, что чтобы аккаунт становился популярным, и охваты росли, видео должны просматриваться пользователями до конца.

«Тик ток» предоставляет пользователям несколько вариантов продвижения. Так что каждый сможет найти наиболее подходящий вариант для себя.

Первый вариант - Hashtag Challenge. Одно из главных направлений для «Тик ток» - это проведение челленджей. Механизм таких флэшмобов работает довольно просто. Пользователь выбирает определенную песню, ставит определённые хэштеги, записывает видео и эти простейшие действия позволяют человеку набрать тысячи, а то и миллионы лайков. Бренды используют такой метод, чтобы повысить свою узнаваемость, узнаваемость продукта или популяризировать его среди аудитории.

Вирусный флэшмоб получил огромный отклик и успех. За полгода общие просмотры подобных видео на платформе приложения превысили 23 миллиарда. Даже с учетом огромного населения Индии это по 20 просмотров на человека. Второй вариант - Topview. Самый простой и наименее энергозатратный метод из всех возможных. При открытии мобильной версии приложения пользователь может видеть статичный баннер, видео или гиф, на весь экран своего телефона. Такая реклама создается и размещается легко, компания просто должна купить место и разработать привлекательную, обращающую на себя внимание картинку. Но есть весомый отталкивающий минус - средний показатель перехода на сторонние сайты, рекламируемые в этом формате размещения - всего $15 \%$.

Третий способ - это продвижение с помощью музыкальных треков. Данный способ подходит для молодых исполнителей, которые хотят побыстрее стать популярными и успешными. Механизм этой схемы работает очень просто. Продюсеры заключают договор с кем-то из успешных контентмейкеров, а они в свою очередь снимают видео или ряд роликов под определенную композицию, тем самым и призывая свою аудиторию снимать похожие видео. Также этим способом зачастую пользуются и популярные группы для рекламирования своего нового сингла или альбома. К примеру, известная по всему миру музыкальная группа LittleBig занималась продвижением своей песни для Евровидения 2020. Таким образом, популярность группы возросла не только внутри русскоговорящей аудитории, но и среди иностранцев, что оказало им огромную поддержку на музыкальном конкурсе.

Четвертый метод - In-feed Native Video. Это формат представляет собой 15-ти секундное видео, которое появляется у пользователя в ленте подписок или в рекомендациях. На данный момент, к сожалению, именно этот способ рекламы пока что доступен не для всех желающих. Все заявки для рекламы рассматриваются вручную разработчиками площадки в течение нескольких дней.

Пятый способ включает в себя нативные размещения у блоггеров. Интеграция - это один из самых известных и используемых способов размещения своей рекламы. Конечно, нужно обратить внимание не на количество подписчиков, и не на количество лайков, а на просмотры и живую аудиторию, то есть - комментарии. Алгоритмы данного приложения работают так, что, если когда-то пользователь хотя бы единожды поставил лайк кому-то из ленты, то новые видео этого создателя контента будут также попадать в ленту рекомендаций человека, совершившие выше прописанные действия.

Так можно сделать вывод, что брендам абсолютно любого уровня и с варьирующейся направленностью 
можно хотя бы попробовать и испытать на себе раскрутку на платформе «Тик ток». Если вы и ваш бренд хотите получить признание у аудитории, то стоит отложить приоритет продаж на второй план и сделать упор на привлечение и дальнейшее развлечение подписчиков. Простой юмор, песни, танцы, конкурсы и челленджи - это то, что является готовой основой для успешного продвижения.

Развлечение ассоциируется, прежде всего, с игровой деятельностью. По мнению авторов исследования этим и объясняется принадлежность «Тик тока» подростковой среде. Именно эта возрастная категория акторов самая восприимчивая к чужим культурам, которые легко пробируются в игровой деятельности. И вместе с тем некоторые исследователи полагают, что «такая открытость и чувствительность к новизне не всегда имеет позитивное значение, особенно когда речь идет об отрицании культурных архетипов собственного этноса и замещении их чужими. Эти явления зримо обнаруживаются в развитии игровой культуры современной молодежи» [4, с.55]. Ана- лизируя онтологию и диалектику «Тик тока» в контексте сетевого медиакоммуникативного пространства можно утверждать о наличие реверсности в характере данного медийного явления. Так, проявляя активность, акторы (а нами уже установлено, что в основном это подростки когнитивная категория с повышенной перцептивной активностью), пытаются таким образом познавать окружающий их реальный и виртуальный миры. Коммуникацию в качестве инструмента миропонимания представляет в своих исследованиях Е.И. Ярославцева. Она утверждает, что в философскую методологию вполне может преобразиться синергетика, как феномен постнеклассическо науки и на этой основе человек способен выстраивать познание окружающего мира [5, с. 8]. Справедливости ради стоит отметить. Что данное проявление коммуникативной активности с целью обследование и адатаптации окружающей среды к различным медиапроявлениям наблюдаются практически на всей территории сетевого медиакоммуникативного пространтства.

\section{ЛИТЕРАТУРА}

1. Фишер К. История новой философии: Рене Декарт: Пер с нем. / К. Фишер. - М.: 000 «Издательство АСТ», 2004. - 492. [4] c. - (Pilosophy).

2. Дмитриев Л.А. Законы драматургии. Теория и метод творчества. / Л.А. Дмитриев. - М.: Диалог-МГУ, 1998. - 124с.

3. Маньковская Н.Б. Эстетика постмодернизма / Н.Б. Маньковская. - СПб Алетейя, 2000. (серия «Gallicinium»). - 347 с.

4. Репринцева Е.А. Современная игровая культура молодежи как феномен теории и практики воспитания: проблемы и тенденции развития//Фундаментальные проблемы культурологи: В 4т. Том III: Культурная динамика / отв. Ред. Д.Л. Спивак. - СПб. : Алетейя, 2008. - 518 с.

5. Ярославцева Е.И. Человек в современной сетевой парадигме: монография / Е.И. Ярославцева. - М.: «Канон+» РООИ «Реабилитация», 2011. - 352 с. 